\title{
Do Bastão de Esculápio ao Caduceu de Mercúrio
}

\author{
Paulo R. Prates
}

Porto Alegre, RS

Os dicionários definem símbolos como "tudo aquilo que, por um princípio de analogia, representa ou substitui alguma coisa. Aquilo que, por sua forma e natureza, evoca, representa ou substitui, num determinado contexto, algo

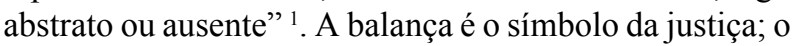
sol é o símbolo da vida; a cruz é o símbolo do cristianismo. Todo o símbolo tem um significado, sem o que ele não pode representar alguma coisa.

O editor da respeitada revista The New England Journal of Medicine, Arnold S. Relman, em seu editorial comemorativo ao volume 300 da revista, refere-se ao seu símbolo, o bastão de Esculápio cruzado com uma pena, como the crossed quill and caduceus seal ${ }^{2}$. Uma quantidade de cartas de médicos americanos e até mesmo de outros países chegou a redação para reclamar da confusão feita com o bastão de Esculápio e o caduceu de Mercúrio.

A confusão entre o bastão de Esculápio e o caduceu de Mercúrio é antiga e existe desde a Renascença ${ }^{3}$. O bastão de Esculápio com uma serpente enrolada sempre foi o símbolo da atividade médica. Em 1919 a American Medical Association e em 1956 a World Medical Association o adotaram como seus símbolos ${ }^{4}$. O caduceu é mais antigo que o bastão de Esculápio e sempre esteve relacionado ao comércio. De onde vem esta confusão entre os dois símbolos?

Mercúrio era filho de Júpiter e de Maia. Os gregos o chamavam de Hermes, que significa interprete ou mensageiro. Logo após seu nascimento revelou extraordinária inteligência. Conseguiu sair do berço e foi para Tessália onde roubou parte dos rebanhos guardados por Apolo e após esconder o gado numa caverna voltou para o berço como se nada tivesse acontecido. Quando Apolo descobriu o roubo conduziu Mercúrio diante de Júpiter que o obrigou a devolver os animais. No entanto, Apolo, encantado com o som da lira que Mercúrio tinha inventado, a partir de uma casco de

Instituto de Cardiologia do Rio Grande do Sul/Fundação Universitária de Cardiologia

Correspondência: Paulo R. Prates - Unidade de Pesquisa do IC/FUC - Av. Princesa Isabel, 395 - 90620-001 - Porto Alegre, RS - E-mail: pesquisa@cardnet.tche.br Recebido para publicação em 13/9/01

Aceito em 14/11/01 tartaruga, deu-lhe em troca, o gado e o caduceu. Júpiter, surpreso com a vivacidade e inteligência do filho, fez dele seu mensageiro e o colocou a serviço de Plutão, deus das profundezas subterrâneas, os infernos, de onde reinava sobre os mortos. Uma das tarefas de Mercúrio era conduzir os mortos ao reino de Plutão ${ }^{5,6}$. Esta é a origem do costume de que na antigüidade, os homens que procuravam os feridos e os mortos nos campos de batalha levassem o caduceu, semelhante à bandeira branca ou à bandeira da cruz vermelha nos conflitos mais recentes ${ }^{7}$. Surgiu daí o fato de ser o caduceu o símbolo de serviços de saúde de algumas forças armadas, inclusive a dos Estados Unidos ${ }^{3}$.

O caduceu era, originalmente, uma haste de ouro com asas em sua extremidade. Segundo a mitologia, Mercúrio lançou-o entre duas serpentes que lutavam e estas se entrelaçaram na haste em uma atitude amistosa ${ }^{6}$. Daí o seu aspecto conhecido. Por ser Mercúrio, também, deus dos negociantes, o caduceu tornou-se o símbolo do comércio (fig. 1) (5, $^{5}$.

A lenda, sobre Asklépios ou Esculápio, data de cerca de 700 anos AC, foi relatada por Hesíodo ${ }^{8}$.

Esculápio, nome latino de Asklépios em grego, era filho de Apolo e Côronis. Nasceu em Epidauro no Peloponeso, de onde seu culto se disseminou. Conta a mitologia que Diana, irmã e uma das esposas de Apolo, numa crise de ciúmes matou a mortal Côronis, grávida de Apolo. Estando Côronis já na pira funerária, Apolo arrancou-lhe do ventre o filho Esculápio, entregando-o ao centauro Quiron para ensinar-lhe a arte de curar. O menino aprendeu depressa e logo ultrapassou o mestre. Tornou-se tão hábil na arte de curar que podia ressuscitar os mortos. Plutão, temeroso de que com esse dom, pudesse Esculápio diminuir as almas que chegavam ao seu reino, queixou-se a Júpiter que, como castigo, o eliminou com um raio. Em outra versão, Esculápio foi morto pelas flechas de seu próprio pai, tendo as flechas de Apolo tornado-se o símbolo da morte súbita na medicina grega $^{4-6,9}$. Numa de suas visitas a pacientes em seu templo, uma serpente enrolou-se em seu cajado. Apesar do esforço para retirá-la, a serpente tornava a enrolar-se no cajado onde permaneceu ${ }^{4}$. Esculápio tornou-se o deus da medicina e seu cajado com uma serpente enrolada, o símbolo da atividade médica (fig. 2) ${ }^{3,4,10}$. 


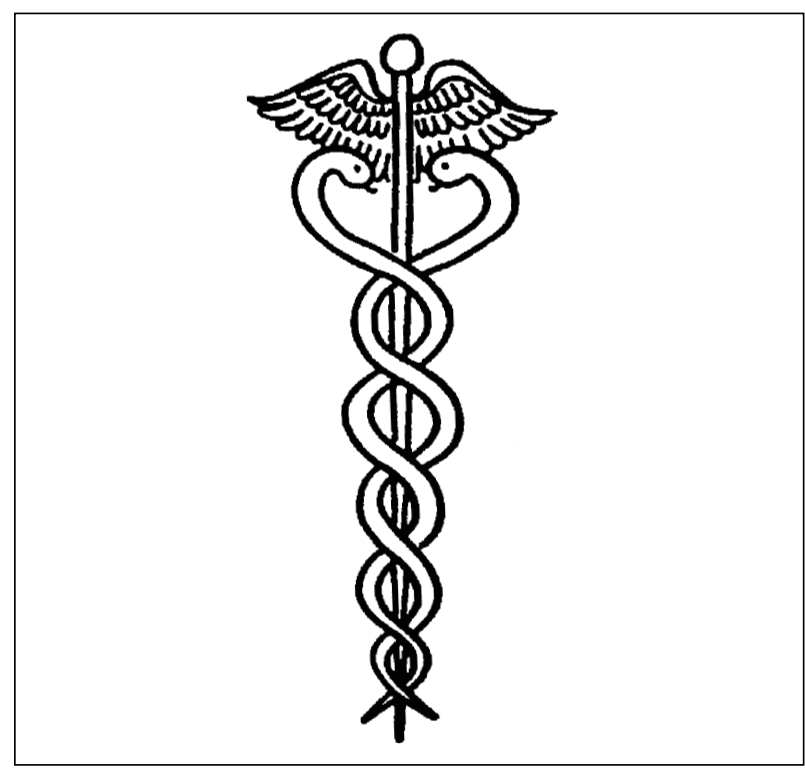

Fig. 1 - O caduceu de Mercúrio, símbolo do comércio

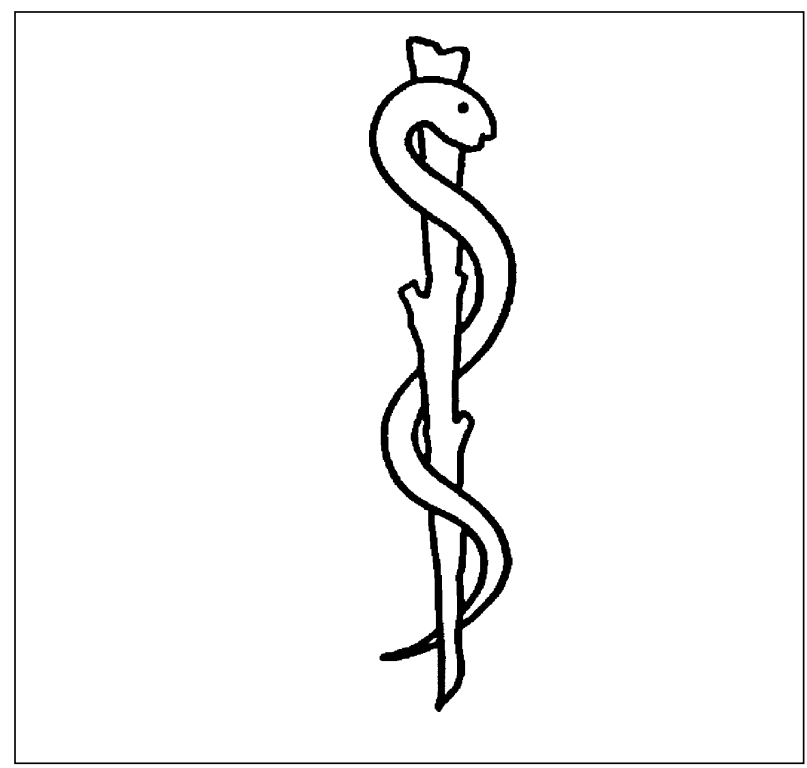

Fig. 2 - O bastão de Esculápio, símbolo da Medicina

De onde vem a confusão entre os símbolos de atividade tão diferentes?

A primeira causa é a serpente que desde o tempo dos babilônios esteve relacionada com a cura e, portanto, com a atividade médica. Na lenda do príncipe Gilgamés, transmitida pela escrita cuneiforme, a serpente, após comer a erva da vida despiu-se de sua pele envelhecida e se rejuvenesceu. Tornou-se o símbolo de vários deuses da cura nas culturas antigas ${ }^{11}$.

A Bíblia, no Quarto Livro de Moisés, 21:8, também se refere à serpente, relacionando-a com a cura: "Então", disse o Senhor a Moisés: "faze uma serpente de bronze e põe-na sobre a haste; e será que todo o mordido que olhar para ela vivera".
Outro motivo é que o caduceu pertencia a Apolo que o deu a Mercúrio em troca da lira. Apolo é também considerado como deus da medicina pelos gregos e considerado o inventor da arte de curar ${ }^{13}$. O juramento de Hipócrates inicia com o juramento em nome de Apolo, "juro por Apolo, médico, Asklépios, Hegéia e Panacéia...” ${ }^{14}$.

O fato de ser usado nos campos de batalhas na procura de feridos e mortos também o confunde com a atividade médica ${ }^{7}$.

Outro fato importante é a associação do caduceu à alquimia na idade média ${ }^{3}$, daí a sua ligação aos medicamentos e a medicina.

Certamente, o motivo principal da confusão nos tempos atuais foi a publicação das obras de Hipócrates em grego pelo tipógrafo suíço Johannes Froben em 1538. O caduceu era o símbolo de sua tipografia e como tal, foi estampado na página frontal do livro (fig. 3) ${ }^{15}$.

Símbolos significam a representação de alguma coisa ou de alguma atividade e podem, em determinado período, perder a sintonia com aquilo que ele representa. $\mathrm{O}$ famoso artista gráfico americano, Paul Rand, nos diz muito bem sobre isto:

"Há bons símbolos, como a cruz.

Há outros como a suástica.

Seus significados são tomados de uma realidade.

Símbolos são uma dualidade.

Eles tomam significado das causas... boas ou más ". ${ }^{16}$

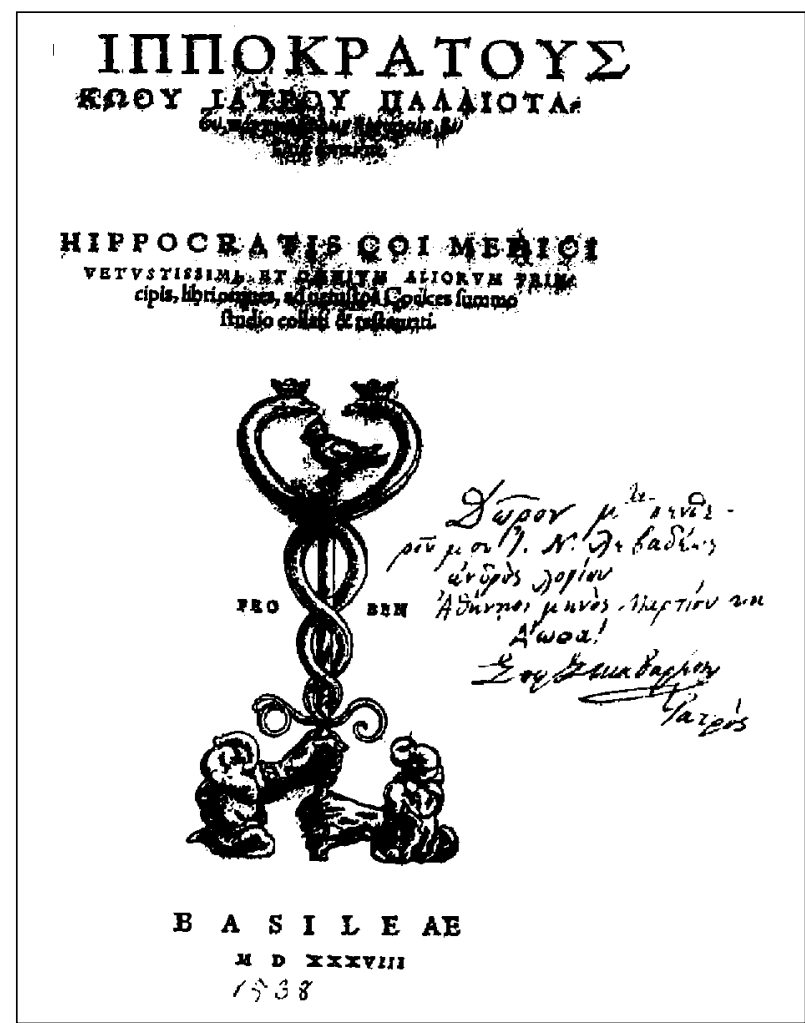

Fig. 3 - Obras de Hipócrates em grego, publicadas pelo tipógrafo suiço Johannes Froben em 1538. 
As mudanças que a realidade econômica tem imposto à atividade médica com a comercialização exagerada da profissão; com planos de saúde impondo normas à nossa atividade e muitos desses planos usando corretamente o caduceu do comércio, como símbolo, mas algumas vezes fazendo com que este seja confundido com o símbolo da medicina, uma reflexão sobre o nosso verdadeiro símbolo e o seu significado se impõe. É pouco provável que seu uso incorreto possa induzir mudanças no comportamento médico. Em seu artigo "O símbolo da medicina: tradição e heresia" o Prof. Joffre Marcondes de Rezende escreve: "com a intermediação dos serviços médicos por empresas de fins lucra- tivos, a medicina tornou-se objeto de comércio por parte de terceiros. O médico passou a ser apenas um prestador de serviços e o paciente um consumidor, ambos sujeitos a normas contratuais previamente estabelecidas. Neste sentido, estaria justificado o uso por essas empresas do caduceu de Hermes, símbolo do comércio" ${ }^{17}$. Por outro lado, não devemos esquecer que a nossa atividade surgiu com o homem, com o primeiro sinal de sofrimento e com o primeiro desejo de aliviá-lo ${ }^{12}$ e outro não deveria ser seu objetivo primordial. Isto não tem nada em comum com o comércio. O bastão de Esculápio e o que ele significa é e deve continuar sendo o verdadeiro símbolo da medicina ${ }^{4,9,18}$.

\section{Referências}

1. De Holanda Ferreira AB. Novo Dicionário da Língua Portuguesa Rio de Janeiro: Nova Fronteira, 1975.

2. Relman AS. Editorial. N Engl J Med 1979; 300: 38-9.

3. Metzer WS. The caduceus and the Aesculapian staff: ancient eastern origins, evolution, and western parallels. South Med J 1989; 82: 743-8.

4. Faria Jr. MA. Vandals at the gates of medicine. Georgia: Hacienda Publishing, 1994.

5. Commelin P. Nova mitologia grega e romana. Belo Horizonte: Itatiaia, 1983

6. Ménard R. Mitologia Grego-Romana. São Paulo: Opus, 1991.

7. Eich WF. The caduceus. Letters to the editor. South Med J 1989; 82: 1455

8. Tamayo RP. El Concepto de Enfermedade. México: DF Fondo de Cultura Económica, 1988.

9. Meade JW. Letters to editor. JAIMA 1989; 262: 1771.
10. Filley CM. Serpents two will not do. N Engl J Med 1979; 300: 929.

11. De Oliveira AB. A evolução da medicina até o início do século XX. São Paulo: Livraria Pioneira, Secretaria de Estudos de Cultura, 1981.

12. Greelhoed GW. The caduceus as a medical emblem: heritage or heresy? South Med J 1988, 81: 1155-61.

13. Castiglione A. História da Medicina. São Paulo: Editora Nacional, 1947.

14. Lyons AS, Petrucelli II RJ. Medicine an Illustrated History. New York: Harry N. Abrams, Inc. Publishers, 1978.

15. Rutkow JM. Surgery an Ilustrated History. Toronto: Mosby, 1993.

16. Os símbolos nacionais. Presidência da República. Brasília, 1993.

17. Rezende JM. O símbolo da medicina: tradição e heresia. Dados obtidos via internet. Web: http://www.usuários.cultura.com.br/jmrezende, 29/10/2001.

18. Parrish DO. The symbol of medicine: one snake, not two. JAMA 1989;261:3412. 